\title{
Informal Social Support and Caregiver Burden of Caregivers of Elderly with Dementia
}

\author{
NurFatihah O,Rahmah M.A\&Rosnah S. \\ Department of Community Health, Faculty of Medicine, National University of Malaysia.
}

\begin{abstract}
Social support is a crucial factor in caregiving of dementia patients. The existence of informal social support has been shown to reduce the caregiver burden. However little is known about itsexistence and its influenceoncaregiver burden of dementia especially in local setting. Therefore the objectives of this study were to identify the association between social support and burden.

Methods: A cross sectional study was done using validated questionnaires via guided interview wasconducted among informal primary caregivers of dementia patients from five major hospitals in Sarawak, Malaysia.

Result: Hundred and forty-five informal primary caregivers were recruited. The overall mean score of social support was $57.1( \pm 13.06)$ whereby $49 \%$ of caregivers perceived that they had good informal social support and $51 \%$ had poor informal social support. There are significant association between informal social support from family and caregiver burden $(p<0.05)$.

Conclusion: These group of caregiversreceived all the informal social support from family, friends and significant others. However it was found that only informal social support from family wasassociated with caregiver burden.Strengthening of family relationship, responsibility and development of formal social support services should exist in addition to help the caregivers whom lack of the social support.
\end{abstract}

Keywords: caregiver burden, dementia, informalsocial support, Malaysia

\section{Introduction}

Social support is defined as a group of individual who can help and support any person ${ }^{[1]}$. Meanwhile informal social support is defined as unpaid help or support from any individual ${ }^{[1]}$. In Asia, particularly East Asia, most of the countries still has filial piety concept, to provide help and assistance to aged parents as acaregiving ideology traditionally ${ }^{[2]}$. For example in Thailand these concepts still exist as a support for financial and emotional and it is the duty of family to take the task of caregiving of dementia patients ${ }^{[3]}$. The tie relationship from one generation to the next one still close and they believed that they are protected from the negative consequences of caregiving ${ }^{[2]}$. Research has been shown that, lack of social support will lead to detrimental effects on our health particularly stress and burden which lead to negative effect on immune system leading to infection ${ }^{[4]}$.They may also be easily frustrated which give rise to negative acts on caregiving such as elderly abuse ${ }^{[5]}$.

In dementia caregiving, caregivers are overwhelm with multitask activities which include activities of care, personal and family matters. As a result they will suffer from physical health problems such as chronic backache, musculoskeletal pain, reduce social activities, poor mental health, cardiovascular problems and poor sleep $^{[6,7,8]}$. Previous studies have shown that these symptoms will give an impact on their quality of life $\mathrm{f}^{[9,10,11]}$. The existence of formal social support was widely available in country like Japan, USA and UK, which gave helps to most of dementia caregivers. However,this type of services was not available in the local setting. Understanding of the informal social support and its influence on caregiver burden locally will provide some information to help this group of caregivers. Therefore the objective of this study is to identify the existence of informal social support and its association withcaregiver burden.

\section{Methodology}

A cross sectional study was conducted among informal primary caregivers of dementia from five psychiatry clinic from major hospitals in Sarawak from May to December 2011. Informal primary caregiver is defined as unpaid caregiver who was the main people who provide most care and assistance in patient daily activities. Sample size was calculated using Kish formula ${ }^{[12]}$. Hundred and forty five sample was chosen purposively from psychiatric clinic attendance as they fulfilled the inclusion criteria. The inclusion criteria were the primary caregivers, above 18 years old and who look after the dementia patient aged 60 years and above with confirmed diagnosis of dementia. The exclusion criteria were non Malaysian, formal maid and taking care for less than 3 months. A pilot testing was done prior to data collection and any error in the questionnaire was adjusted. Data were collected viaguided interview either in the psychiatric clinic or home visit using a set of 
validated questionnaires containinginformation regarding respondents' socio-demographic, Multidimensional Scale Perceived Social Support(MSPSS) and Zarit's Burden Interview (ZBI)for caregiver burden.

MSPSS was developed in other country and it was validated in Malaysia ${ }^{[13,14]}$ and has a good internal reliability with Cronbach's alpha $=0.89$, parallel form reliability $(0.94)$ and test-retest reliability $(0.77)^{[14]}$. It has three component of support which are from family, friend and significant others.It has 12 items: 4 for family, 4 friends, and 4 significant others (see Table 1). Items were measured on a 7-point scale from 1 strongly disagree to 7 strongly agree. It provides four scores: family, friends, significant others and total. Higher score indicate higher perceived social support. For the purpose of analysis the mean of total social support score was taken as reference point. Any caregiver whom scored more than mean score was considered to have perception of good social support. Meanwhile if they had scores less than the mean score they were considered to have perception of poor social support.

Zarit's Burden Interview is uni-dimension questionnaires which measures the burden and has its own strength as it can evaluate the origin of burden in diversify manner ${ }^{[1]}$. It is among the famous measure to evaluate burden due to its reproducibility and validity ${ }^{[1]}$. It was also used by one local study ${ }^{[15]}$. This measurement contain 22 items using Likert scale from 0 to $4(0=$ never, $1=$ seldom, $2=$ sometimes, $3=$ frequent, $4=$ always), measuring how caregiving affecting their life. The score range from 0 to 88 . The burden were categorized into 0 to 20 was low or no burden, 21 to 40 was mild to moderate, 41 to 60 was moderate to high and 61 to 88 was severe ${ }^{[13]}$. It has been translated into Malay language and validated with internal consistency withCronbach's alpha of 0.88 and has good test-retest reliability with alpha of $0.91^{[1]}$.

Data were analysed using Statistical Package for Social Science (SPSS) programme version 19. Descriptive analysis was done and multiple linear regressionswas preceded once the assumptions fulfilled in order to determine the relationship between social support and caregiver burden. The significant level was set at $\mathrm{p} \leq 0.05$. Ethical approval was obtained from National University of Malaysia Ethical Committee and National Medical Research Registry of Malaysia.

MSPSS items
Item no.
Family subscale
1. My family really tries to help me
2. I get the emotional help and support I need from my family
3. I can talk about my problems with my family
4. My family is willing to help me make decisions
Friends subscale
5. My friends really try to help me
6. I can count on my friends when things go wrong
7. I have friends with whom I can share my joys and sorrows
8. I can talk about my problems with my friends
Significant other subscale
9. There is a special person who is around when I am in need
10. There is a special person with whom I can share my joys and sorrows
11. I have a special person who is a real source of comfort to me
12. There is a special person in my life who cares about my feelings

Table 1: Multidimensional Perceived Social Support Scale

\section{Results}

Table 2 showed a total of 145 caregivers of elderly with dementia participated in this study. The age ranges of caregivers were 19 to 90 years old with the mean of 55( \pm 15.86$)$. Meanwhile the mean age for patient was $74.9( \pm 8.47)$ with range from 60 to 97 years old. The majority of caregivers were female $(73.8 \%)$. In term of ethnicity, Chinese were the majority (57.2\%), followed by Malay (16.6\%), Iban (13.8\%) and $12.4 \%$ were Bidayuh, Melanau and others. Most of the caregivers were married $(89.7 \%)$ and $11.3 \%$ remained single. Meanwhile the education level of caregivers were $22.8 \%$ with no formal education, $27.6 \%$ attended primary school, $38.6 \%$ attended secondary school and $11.0 \%$ had college or university education.

About $72.4 \%$ of caregivers were unemployed and $17.6 \%$ of them were employed. The reason of unemployment was due to majority were housewife. The employed caregivers had following occupations such as labourer, clerk, teacher, community nurse, sales representative and doing business. Forty nine per cent of caregivers perceived they had good social support, meanwhile $51 \%$ perceived they had poor social support. The prevalence of severe burden was $21.4 \%$, followed by $41.4 \%$ moderate burden, $19.3 \%$ with low burden and $7.6 \%$ with no burden. There was significant association between social support from family and caregiver burden $(\mathrm{p}=0.026)$ (see Table 3$)$. 
Informal Social Support and Caregiver Burden of Caregivers of Elderly With Dementia

\begin{tabular}{|c|c|c|c|}
\hline Variables & $\begin{array}{l}\text { Caregiver } \\
\text { n }(\%)\end{array}$ & $\begin{array}{l}\text { Care recipient } \\
\text { n }(\%)\end{array}$ & Mean (sd) \\
\hline \multicolumn{4}{|l|}{ Age (years) } \\
\hline $18-30$ & $5(3.4)$ & & \\
\hline $31-40$ & $19(13.1)$ & & \\
\hline $41-50$ & $43(29.7)$ & & $55( \pm 15.8)$ \\
\hline $51-60$ & $30(20.7)$ & & \\
\hline$>60$ & $48(33.1)$ & & \\
\hline $60-70$ & & $48(33.1)$ & \\
\hline $71-90$ & & $91(62.8)$ & $74.9( \pm 8.4)$ \\
\hline$>90$ & & $6(4.1)$ & \\
\hline \multicolumn{4}{|l|}{ Gender } \\
\hline Male & $38(26.2)$ & $62(42.8)$ & \\
\hline Female & $107(73.8)$ & $83(57.2)$ & \\
\hline \multicolumn{4}{|l|}{ Race } \\
\hline Chinese & $83(57.2)$ & $77(53.1)$ & \\
\hline Malay & $24(16.6)$ & $26(17.9)$ & \\
\hline Iban & $20(13.8)$ & $19(13.1)$ & \\
\hline Bidayuh & $15(10.3)$ & $15(10.3)$ & \\
\hline Melanau & $2(1.4)$ & $3(2.1)$ & \\
\hline Others & $1(0.7)$ & $5(3.4)$ & \\
\hline \multicolumn{4}{|l|}{ Marital status } \\
\hline Married & $130(89.7)$ & $83(55.9)$ & \\
\hline Single & $15(10.3)$ & $64(44.1)$ & \\
\hline \multicolumn{4}{|l|}{ Education } \\
\hline Informal & $33(22.8)$ & $100(69.0)$ & \\
\hline Lower & $96(66.2)$ & $41(28.3)$ & \\
\hline Tertiary & $16(11.0)$ & $4(2.8)$ & \\
\hline \multicolumn{4}{|l|}{ Employment } \\
\hline Employed & $40(27.6)$ & & \\
\hline Unemployed & $105(72.4)$ & & \\
\hline \multicolumn{4}{|l|}{ Household income } \\
\hline$<770$ & $42(29.0)$ & & \\
\hline$\geq 770$ & $103(71.0)$ & & \\
\hline \multicolumn{4}{|l|}{ Relationship } \\
\hline Spouse & $54(37.3)$ & & \\
\hline Non spouse & $91(62.7)$ & & \\
\hline \multicolumn{4}{|c|}{ Informal Social support } \\
\hline Family & & & $21.1( \pm 5.1)$ \\
\hline Friends & & & $15.3( \pm 5.8)$ \\
\hline Significant others & & & $20.6( \pm 5.3)$ \\
\hline \multicolumn{4}{|c|}{$\begin{array}{l}\text { Informal Social support score } \\
\text { category }\end{array}$} \\
\hline Good & $71(49)$ & & \\
\hline Poor & $74(51)$ & & \\
\hline \multicolumn{4}{|l|}{ ZBI Score } \\
\hline No burden & $20(13.8)$ & & \\
\hline Mild & $43(29.7)$ & & $46( \pm 17.0)$ \\
\hline Moderate & $51(35.2)$ & & \\
\hline Severe & $31(21.4)$ & & \\
\hline
\end{tabular}

Table 2: Socio-demographic profiles of caregivers and care recipients, social support score and ZBI score. 


\begin{tabular}{llllll}
\hline Variables & $\begin{array}{l}\text { Unstandardized } \\
\text { Coefficients } \\
\text { B }\end{array}$ & Std. Error & $\mathbf{t}$ & p value & (95\% CI) \\
\hline Constant & 61.44 & 6.58 & 9.34 & $\mathbf{0 . 0 0 0}$ & $(48.4,74.4)$ \\
Family & -0.79 & 0.35 & -2.25 & $\mathbf{0 . 0 2 6 * *}$ & $(-1.48,-0.09)$ \\
Friends & -0.512 & 0.274 & 1.87 & $\mathbf{0 . 0 6 4}$ & $(-0.03,1.054)$ \\
Significant others & -0.32 & -0.09 & 0.90 & $\mathbf{0 . 3 6}$ & $(-1.01,0.37)$ \\
\hline
\end{tabular}

**significant level at $\mathbf{p} \leq \mathbf{0 . 0 5}$

Model fit; adjusted $R^{2}=27.4 \%$, assumption met, no interaction, no multicollinearity.

Table 3: Association BetweenInformal Social Support and Caregiver Burden

\section{Discussion}

Result of this study showed that most of the caregivers received informal social support from family as compared to friends and significant others. It was probably related to the majority of caregivers were Chinese. It was mentioned that Chinese practised traditional social network among the family members especially the filial piety concepts which derived from Confucius belief ${ }^{[16]}$. However contradict findings in one study in Hong Kong had showed that they experienced less burden not solely because of social support but also related to coping mechanism, adaptation and other factors ${ }^{[17]}$. Other than Chinese belief, family support and relationship for example husband helps in physical activities were very important in lifting the bed ridden demented patient which helps to reduce the caregiver physical burden. Poor family relationship resulting in poor social support was found to be a significant factor in determining the early institutionalization of dementia patients ${ }^{[18]}$.

There was significant association between social support and caregiver burden. It showed that the higher social support received from family the lower the caregiver burden and vice versa. This result is consistent with local study in which they found that caregivers received good informal social support experience less burden ${ }^{[1]}$. Casado and Sacco ${ }^{[19]}$ had found that good family support, understanding and patient selfmanagement were related to less burden. In one study it was found that informal social support was mentioned as resources for caregivers to alleviate or lessen the burden ${ }^{[20]}$. Apart from low burden, the patient outcome was found to be good in caregivers with good informal support ${ }^{[20]}$. Therefore it was an important act to provide social support for this group of population. In a community which has proper linkage of social support for example the availability of temporary care facilities or respite care, carer has good social support thus lower their burden and improve their quality of life ${ }^{[21]}$.

Other than informal social support, it was known that caregiver support group had also contributed psychological, advices, emotional support which helps to alleviate the burden ${ }^{[22]}$. Activities like home visit can be arranged to help the caregivers whom stay far from local support group or health facilities. Both of these activities can be arranged in the local setting as one method to support the caregivers.

There are a variety of factors which may contribute towards the limitations of this study. First, this is cross sectional study therefore it was unable to provide the causal relationship between social support and caregiver burden. A second limitation of this study concerns about purposive sampling, thus the result could not be generalized. It was unavoidable due to small sample of dementia patients.Despite the study limitations, in this study population showed that there was significant severe burden and higher number of them perceived that they had poor social support.

\section{Conclusion}

Social support from family was associated with caregiver burden in this study. Strengthening family relationship and supporting their effort should be done via community based formal support services. Community based support interventionfor example support group should exist in order to help the caregivers with poor social support and high burden.

\section{Acknowledgement}

Authors would like to thanks to Director General of Health Malaysia for permission to publish this paper. 


\section{References}

[1] Choo, W.Y., Karina, R., Poi, P.J.H., Ebenezer, E., \& Prince, M.J. Social Support and Burden among Caregivers of Patients with Dementia in Malaysia.Asia Pac J Public Health, 2003, 15(1): 23 - 29.

[2] Siew,T. T., Chung, Y.L. \& Yen, C. L. Factors associated with depressive distress among Taiwanese family caregivers of cancer patients at the end of life. Palliative Medicine, 2007, 21: 249-257.

[3] Rarcharneeporn, S.and Lund, D.A..Maintaining Caregiving at Home: A Culturally Sensitive Grounded Theory of Providing Care in Thailand.J.Transcult.Nurs.,2000, 11: 166-175.

[4] Devor, M. \&Renvall, M. An Educational Intervention to Support Caregivers of Elders With Dementia. Am J Alzheimers Dis Other Demen, 2008, 23: 233-241.

[5] Kuo, F. \& Fisher, G. Meeting the needs of caregivers with Alzheimer's disease:Recommendations for health care providers. Californian Journal of Health Promotion, 2004, 2(3), 82-91.

[6] Thompson, T., Pierce, L., Steiner, V., Govoni, A., Hicks, B., \&Friedemann, M.L. What happened to normal? Learning the role of caregiver.Online Journal of Nursing Informatics, 2004, 8(2):http://www.eaa-knowledge.com/ojni/ni/8_2/caregiver.htm

[7] Beaudreau, S. A., Spira, A.P., Gray, H.L., Depp, C.A., Long, J., Rothkopf, M. \&Gallagher-Thompson, D. The Relationship BetweenObjectively Measured Sleep Disturbance and Dementia Family Caregiver Distress and Burden.JGeriatr Psychiatry Neurol, 2008, 21(3): 159-165.

[8] Arango-Lasprilla, J.C., Moreno, A., Rogers, H. and Francis, K. The Effect of Dementia Patient's Physical, Cognitive, and Emotional/ Behavioral Problems on Caregiver Well-Being: Findings From a Spanish-Speaking Sample From Colombia, South America. AM J Alzheimers Dis Other Demen, 2009, 24: 384-397.

[9] Schulz,R., McGinnis, K.S., Shong Zhang, Martire, L.M., Hebert, R.S., Beach, S.R., Zdaniuk, B., Czaja, S.J. \& Belle, S.H. Dementia Patient Suffering and Caregiver Depression.Alzheimer Dis AssocDisord, 2008, 22(2): 170-176.

[10] Hughes, S. L., Giobbie-Hurder, A., Weaver, F.M., Kubal, J.D. \& Henderson, W. Relationship Between Caregiver Burden and Health-Related Quality of Life. The Cerontologist, 1999, 39(5): 534-545.

[11] Arango-Lasprilla, J.C., Lehan,T., Drew, A., Moreno, A. , Deng Xiaoyan\&Lemos, M. Health-Related Quality of Life in Caregivers of Individuals With Dementia From Colombia. American Journal of Alzheimer's Disease \& Other Dementia, 2010, 25(7): 556-561.

[12] AzmiMohd Tamil. Calculate your own sample size. Kuala Lumpur: Secretariat of Medical Research \& Industry, UKM Medical Centre (UKMMC), 2008

[13] Zimet, G.D., Dahlem, N.W., Zimet, S.G. \& Farley, G.K. The Multidimensional Scale of Perceived Social Support. Journal of Personality Assessment, 1988, 52, 30-41.

[14] C.G. Ng, A.N. AmerSiddiq, S.A. Aida, N.Z. Zainal, O.H. Koh. Validation of the Malay version of the Multidimensional Scale of Perceived Social Support (MSPSS-M) among a group of medical students in Faculty of Medicine,University Malaya. Asian Journal of Psychiatry,2010, 3(1), 3-6.

[15] Tuan Zailina Tuan Ngah. A Study on Burden Among Caregivers of Patient with Dementia in Hospital UniversitiSains Malaysia Kelantan. Master Thesis.UniversitiSains Malaysia, 2008.

[16] Lai, W.L. Filial Piety, Caregiving Appraisal and Caregiving Burden. Research on Aging, 2010, 32(2), $200-223$.

[17] Chan, W.C., Ng, C., Mok, C.C.M., Wong, F.L.F., Pang, S.L \& Chiu, H.F.K. Lived Experience of Caregivers of Persons with Dementia in Hong Kong: A Qualitative Study. East Asian Archives of Psychiatry,2010,20(4):163-168.

[18] SpitznagelM.B., Tremont G., Davis J.D. \& Foster, S.M. Psychosocial Predictors of Dementia Caregiver Desire to Institutionalize: Caregiver, Care Recipient, and Family Relationship Factors. J Geriatr Psychiatry Neurol, 2006, 19(1), 16-20.Chou, K. R., Chu, H., Tseng, C.L. \& Lu, R.B.The Measurement of Caregiver Burden.J Med Sci., 2003, 23(2) :73-82. http://jms1.ndmctsgh.edu.tw/2302073.pdf. [8 Dec 2010].

[19] Casado, B., \& Sacco, P. Correlates of caregiver burden among family caregivers of older Korean Americans. The Journals of Gerontology, Series B: Psychological Sciences and Social Sciences, 2011,1-6.

[20] Iecovich E. Caregiving Burden, Community Services and Quality of Life of Primary Caregivers of Frail Elderly Persons. Journal of Applied Gerontology, 2008, 27; 309-332.

[21] Raivio, M., Eloniemi-Sulkava, U., Laakkonen, M., Saarenheimo, M., Pietilä, M., Tilvis, R.\&Pitkälä, K. Alzheimer's Disease?Am J Alzheimers Dis Other Demen, 2007, 22: 360-370.

[22] Gitlin, L.N., Winter, L., Dennis, M.P., Hodgson, N. \& Hauck, W.H. 2010. A Biobehavioral Home- Based Intervention and the Well-being of Patients With Dementia and Their Caregivers: The COPE Randomized Trial. JAMA,304(9):983-991. 